D.O.I.: $10.3895 /$ gi.v12n4.4852

\title{
ESTUDO DO MAPEAMENTO DE FLUXO DE VALOR NA FORMAÇÃO DE CABEDAL DE CALÇADOS FEMININOS
}

\section{STUDY OF VALUE STREAM MAPPING IN FORMATION OF FEMALE LEATHER SHOES}

\author{
Wagner Pietrobelli Bueno ${ }^{1}$, Cristiano Henrique Antonelli da Veiga ${ }^{2}$ \\ ${ }^{1}$ Universidade Federal de Santa Maria - UFSM - Santa Maria/RS \\ wbpietro@outlook.com \\ ${ }^{2}$ Universidade Federal de Uberlândia - UFU - Uberlândia/MG \\ chadaveiga@ufu.br
}

\begin{abstract}
Resumo
Exalta-se a importância de buscar inovações em processos e operações que possam satisfazer as empresas e clientes, por meio de oferecimento de produtos e serviços. O presente estudo mensurou o processo atual de fabricação do cabedal de calçado feminino e seus dados tabulados em planilhas eletrônicas, propõe melhorias ao processo atual baseado nos conceitos de mapeamento de fluxo de valor. Esta proposição está alinhada aos conceitos Lean Manufacturing e servirão para tomada de decisão a uma empresa sistemista de uma fabricante de calçados. Neste estudo algumas ferramentas foram propostas por meio de métodos kanban, o tempo de ciclo das operações, tempo de setup, e balanceamento das linhas de produção com redução de possíveis gargalos. Verificou-se que por meio da inserção destas ferramentas a empresa poderá apresentar uma redução de estoques inoportunos, melhoria no fluxo do processo produtivo, redução dos problemas de qualidade do produto os quais ocasionarão melhores resultados para a organização.
\end{abstract}

Palavras-chave: Mapeamento de fluxo de valor; manufatura enxuta; produção; calçados; kanban.

\section{Aspectos introdutórios}

As características do mundo empresarial neste início de século XXI são marcadas por meio de constantes mudanças produtivas com distintas técnicas organizacionais sendo frequentemente implantadas, com o uso de novas tecnologias e estudos de pesquisa abordados, incrementando com isso a competitividade acirrada no elo das organizações (CONINCK et al., 2016; VILAR et al., 2016).

Assim, os gestores necessitam ter uma visão ampla e sistêmica, para poder enxergar as qualidades e corrigir os defeitos fabris assiduamente verificados, além de estarem atentos às inovações e lançamentos ocorridos no mercado (CARVALHO, 2010; KILIC; ALTINTAS, 2016). 
O que poucos conseguem ver e que por traz disso o processo evolutivo tem-se mostrado eficiente em métodos e técnicas pelo uso de uma gestão administrativa pouco vista externamente, mas que faz toda diferença nas operações internas das organizações. Trabalhar com produção, presentemente nas fábricas, se transformou em uma incógnita, porque os elos de processos estão se tornando cada vez mais flexíveis, velozes e próximos dos clientes.

De acordo com as questões produtivas em pauta, ao utilizar-se do mapeamento de valor, os gestores de uma empresa, podem identificar, no seu chão de fábrica, as falhas e, a partir destas, estabelecer melhorias do processo e das operações da produção. Seguindo neste contexto, é necessário o uso de mecanismos para se identificar falhas nas atividades atuais, bem como definir e implantar ações de transformações individuais ou coletivas de trabalho com vistas a aumentar a eficiência global da organização.

Segundo Pattanaik (2008) comenta no entendimento de manufatura enxuta, dando ênfase ao conceito que as indústrias são impulsionadas pela demanda da produção, em oposição à fabricação de lotes-bases com técnicas em cronoanalises individualizadas de operações.

Para isso a ferramenta Takt-Time tem como base, ajudar nas decisões concretizadas por produção enxuta, e seus planejamentos julga-se assim, uma ferramenta que auxilia nas operações em cronoanalise, no que menciona Oliveira (2012), complementando a importância em realizar estudos que qualificam os fluxos dos processos e das operações nas indústrias. Também faz-se necessário outro tipo de envolvimento dos trabalhadores, pois estes representam um dos aspectos que influenciam para os resultados da produção enxuta (OHNO, 2006; KOO; KOH; LEE, 2011; SOUZA; RACHID, 2016).

Diante do exposto, este trabalho tem por finalidade apresentar o estudo realizado em uma fabricante que processa distintas peças para a formação de cabedais de calçados feminino - ciclo produtivo de calçados com os setores de corte e chanfração - no que foram descritos pontos que podem ser aperfeiçoados nos processos, em um contexto geral, prestando uma visão técnica e colaborativa para com a organização. Ao finalizar a fabricação das peças, as envia para outras linhas produtivas que tem por ventura montar os cabedais dos calçados, no qual, para a realização destas peças, os procedimentos e métodos são configurados por meio da parceria com uma empresa âncora.

\section{Mapeamento do fluxo de valor (MFV)}

A visão central do mapeamento do fluxo de valor permite uma identificação de atividades que agregam das que não podem agregar valor ao produto final. A importância de fazer um 
mapeamento organizacional ou de um setor em específico, porque os fatores que geram dificuldades são muitas vezes complexos de perceber, e poderão ser configurados e ajustados por meio de um mapeamento de fluxo de valor (MIZOGUCHI; JARDIM; COSTA, 2010; VEIGA; CERESA, 2013).

Quando há um mapeamento de processo, o objetivo é obter um consenso dos pontos a serem atacados tanto no mapa da circunstância que a fábrica está no momento atual, quando no mapa que pretende-se evoluir no futuro (GUERRINI et al., 2014; THANKI; THAKKA, 2014).

Uma das principais limitações que envolvem o mapeamento é a evolução que vai atingir toda a organização com as técnicas de manufatura enxuta, e em todos os níveis entrelaçados (WEGNER et al., 2016).

Guerrini et al., (2014), indica o sistema de produção enxuta como utilização de recursos menores de entrada para satisfazer as mesmas saídas, de forma muito igual a produção em massa, mas de método de escolha que focaliza o cliente final, buscando simultaneamente um conceito de melhoria radical.

Ao abordar as fases do desenho atual da empresa e do desenho futuro, como embora identificar a família dos produtos, e quais deverão ser os planos de implementações adotáveis para o sistema (ROTHER; SHOOK, 2003; WU, 2014).

A inspeção automática notada por colaboradores pode ser considerada como um feedback imediato para que se tenha controle sobre as peças que precisarão ser fabricadas. Este método faz com que antecipe as futuras falhas e assim não sobrepor aos demais setores, tornando assim uma vantagem produtiva, inibindo despesas de possíveis peças defeituosas. Segundo Shingo (1996a), os trabalhadores devem fazer uma inspeção em nas produções antes mesmo passarem para a próxima operação, em que um inspeciona o outro seguidamente.

A ajuda desta ferramenta, orientando a todos os envolvidos da importância de uma suposta falha produtiva, ajudará o elo fabril há ter menos tempo perdido, e, matéria prima muitas vezes reaproveitada, voltando a operações anteriores para ajustar os erros, impedindo esta peça que siga caminho, tendo como uma quebra em futuros problemas, pelo meio de inspeções (SOUZA; RACHID, 2016).

Ao comentar sobre balanceamento, enfatiza-se que todos os setores envolventes da produção precisam buscar uma fabricação setorial de igual para igual, com isso um ambiente de balanceamento procura inibir estoque de lotes nos processos, propondo uma utilização de estoque zero (SHINGO, 1996).

Com isso, o que pode ocorrer em determinado modelos de balanceamento e a habilidade em destaque dos colaboradores quanto aos demais, podendo ocorrer ociosidades de lotes parados, mas o balanceamento tem o efeito de corrigir estes detalhes. 
De acordo Tubino (2007, p.103) "o sistema produtivo está voltado para atender sobre encomenda, o foco da programação da produção deixa de ser administração de materiais [...] e passa a ser administração de capacidade produtiva".

Em conversação, define Shingo (1996, p. 61), "balancear as quantidades significa que quantidades iguais são produzidas em cada processo; isso envolve equilibrar as quantidades de produção e as capacidades de processamento".

Segundo Tubino (2007) coloca o balanceamento com operações padronizadas de trabalho, conforme necessita a linha do produto, chamando (ROP) de rotina de operações padrões, (TC) tempo de ciclo do produto acabado, e (TD) tempo disponível e (PA) plano mestre de produção.

O método utilizado correspondente a operações em linha torna-se uma vantagem quantitativa e qualitativa para a produção, que tende a diminuir tempos ociosos no intermédio das operações, utilizando uma sistemática associada à demanda.

De acordo com Peinado e Graeml (2007, p.104) “o balanceamento da linha de produção, consiste na atribuição de tarefas às estações de trabalho que formam a linha que todas as estações demandem o mesmo tempo para a execução", ou seja, um trabalho que ao ser realizado de forma conjunta e participativa dos colaboradores em um processo de balanceamento contínuo, tem como objetivo, ajustar da melhor maneira possível os setores determinando os tempos, movimentos, layouts e organização de toda a linha.

Entendem-se que para se produzir a defeitos zero, adequando simultaneamente processos, passiveis de serem os mais próprios para a produtividade em certos momentos, mas um detalhe neste momento é a frequência em que nossas maquinas de fabricação irão estar em tempo parado para manutenção e ou ajusta-las.

Neste intercâmbio de informações operacionais surgem os usos dos setups para possivelmente ajustar estes pequenos intervalos que podem causar um diferencial para a fábrica. Dar-se a importância de levantar esta ideia empírica de possível aplicação para a empresa minuciosamente estudar o método correto e verificar como a partir de determinado ponto da pesquisa podem-se aplicar esta pequena operação de tamanha relevância (RITZMAN; KRAJEWSKI, 2004).

Shingo (1996) afirmar a aplicação da operação setup processada corretamente, tenderá á um aumento no tamanho dos lotes e os custos aparentemente baseados em mão de obra serão reduzidos. Esta é a razão pela qual a empresa precisaria maximizar o tamanho de seus lotes devido à proporção de unidades fabricadas. A ideia não é recomendar a organização a ter um sistema $100 \%$ em lote econômico, mas sim uma redução drástica de tempos de setup. 
No entanto, em distintas operações industriais, com o tempo de produtividade longa, aumentar a frequência dos setups corretivos das máquinas pode resultar em desperdícios e custos altos de tempo tanto para funcionários como nos equipamentos.

\section{Método de pesquisa}

O estudo teve como objetivo central identificar o mapeamento de fluxo de valor atual por meio da configuração das atividades realizadas na organização, tendo em vista as melhorias dos processos operacionais de montagem do cabedal de calçados femininos.

Para isto realizou-se a identificação dos processos, sendo eles subdividindo-os em operações, em que o melhor método de estudo na cadeia, foi esclarecido diretamente para os gestores, em que os mesmos poderão adotar a proposta realizada pelo estudo. Para Martins e Laugeni (2006) o estudo de metodologia e seus equipamentos são diferidos de cronometro de horas centesimal, filmagens folha de observação, e pranchetas para observação. Métodos que por convenção prévia na organização será realizada.

Conforme Marconi e Lakatos (2010), a abordagem adotada para a questão, foi a qualitativa, o que precisamente tem um envolvimento nas percepções, buscando um entendimento nos resultados subjetivos. Utilizando uma empresa sistemista da fábrica de Calçados, como referência deste estudo, situada na cidade de Nova Hartz - RS, que tem como principal função prestar fabricação do cabedal do calçado, no período de janeiro a fevereiro 2014. Para o levantamento de dados foi elaborada uma planilha de coleta de dados ilustrada pelo Quadro 1.

\begin{tabular}{|c|c|c|c|c|c|c|c|c|c|c|}
\hline \multirow{2}{*}{$\begin{array}{c}\mathbf{N}^{\mathbf{o}} \\
\text { máquin } \\
\text { as }\end{array}$} & \multirow[t]{2}{*}{$\begin{array}{l}\text { Prod. Por } \\
\text { operação }\end{array}$} & \multirow{2}{*}{$\begin{array}{c}\text { Tempo } \\
\text { Setup } \\
\text { lote }\end{array}$} & \multirow{2}{*}{$\begin{array}{c}\text { Total } \\
\text { Tempo } \\
\text { lote }\end{array}$} & \multirow[t]{2}{*}{$\begin{array}{l}\text { Pares por } \\
\text { hora }\end{array}$} & \multirow[t]{2}{*}{$\begin{array}{l}\text { Pares por } \\
\text { dia }\end{array}$} & \multirow[t]{2}{*}{$\mathbf{N}^{0}$ pessoas } & \multirow[t]{2}{*}{$\begin{array}{c}\text { Prod. Por } \\
\text { pessoas }\end{array}$} & \multicolumn{2}{|c|}{$\begin{array}{c}\text { Qualidade } \\
\text { M.O.D }\end{array}$} & \multirow{2}{*}{$\begin{array}{c}\text { Sugestões } \\
\text { propostas } \\
\text { como } \\
\text { melhorías }\end{array}$} \\
\hline & & & & & & & & Sim & Não & \\
\hline 1 & Passar Cola & 3 & 1 & 4 & 375 & 3000 & 2 & 1 & 0 & \\
\hline 2 & Chanfrar & 2 & 1 & 3 & 500 & 4000 & 3 & 1 & 2 & \\
\hline 3 & Numerar & 2 & 3 & 5 & 300 & 2400 & 2 & 1 & 0 & \\
\hline 4 & Cortar & 4 & 1 & 5 & 300 & 2400 & 4 & 4 & 0 & \\
\hline 5 & Concerto & 5 & 1 & 6 & 250 & 2000 & 1 & 1 & 0 & \\
\hline 6 & Colocar cravos & 6 & 1,5 & 7,5 & 200 & 1600 & 3 & 1 & 2 & \\
\hline
\end{tabular}

Fonte: Os autores.

Neste ponto, a ideia de metodologia foi de pesquisa realizada com base em dados primários, sendo eles coletados por meio de questionários, entrevistas, analise visual e monitoramento diretamente dentro da fábrica. Para isto a pesquisa foi organizada em cinco etapas sendo elas: i) elaboração do plano de trabalho; ii) levantamento das informações; iii) com a coleta já realizada, analisou-se estes fenômenos; iv) conclusão do artigo por meio dos dados da pesquisa coletados; e v) elaboração e encaminhamento de propostas de melhorias para, os gestores, concluindo as fases de estudos na organização. 
Neste contexto, ocasionou-se a possibilidade de medir a ociosidade de colaboradores em operações não necessárias e sem valor, identificação dos processos com gargalos para um balanceamento de linha, e o número de operadores com qualidade para executar as tarefas, o que neste ponto é o mais importante para um sucesso futuro na realização de melhorias oferecidas.

\section{Resultados e análises}

O estudo desenvolvido trata das questões dos processos e operações de uma empresa sistemista do ramo calçadista, denominada tecnicamente como um prestador de serviços do ramo coureiro e sintético, denominada de Atelier de corte e chanfração, com aproximadamente 60 colaboradores. Esta empresa é uma das terceirizadas parceiras de um grupo calçadista denominado de âncora, ambas localizadas na região do polo industrial manufatureiras de calçados de Nova Hartz - RS.

Para isso, toda produção escoada, é por meio de uma parceria de prestação de serviços entre a empresa âncora e suas sistemistas, a qual fornece a matéria prima e maquinários, definindo quais modelos deverão ser fabricados e para qual momento devem ser confeccionados os cabedais dos calçados.

Na geração de inovação produtiva da fábrica, a empresa âncora encaminha seus supervisores de qualidade e produção, os quais tem a função de preparar e repassar aos colaboradores da indústria, como eles podem buscar a produção de 2400 pares dia e de qual maneira mais eficiente possível para realização deste procedimento.

Um ponto importante que é agregado na organização é a subdivisão implantada no contexto da fábrica sistemista, no que envolve duas linhas que trabalham em conjunto com as mesmas operações e processos, mas com modelos de produtos totalmente distintos, para fazer uma escoação de produção abrangente.

Esta subdivisão se dá pelo espelhamento do ambiente interno da empresa âncora existem inúmeras linhas de produção ou "fábricas internas" que trabalham cada qual com a determinada operação, supostamente por esta análise é que se dá a ênfase para a colocação das linhas subdivididas internamente denominadas de fábrica 107 e 108, as quais são abastecedoras constantes da produtividade da empresa âncora.

Ao se observar aárea interna da organização sistemista, nota-se que não há diferença de localização das fábricas 107 e 108, pelo fato da infraestrutura ser pequena, no qual os gestores organizaram de uma forma melhor possível, mas que apresenta uma produção empurrada em linha. Os ambientes que envolvem a fábrica se alteram de acordo com as estações do ano (inverno e verão) exigindo flexibilidade no layout e nos processos. 


\subsection{Mapa de Fluxo de Valor (MFV) atual}

O mapa de fluxo de valor (MFV) é a utilização de técnicas capazes de identificar e diagnosticar restrições não observadas pela organização, de maneira a apontar os possíveis defeitos nos processos e ajusta-los quando necessário. Um sistema produtivo típico é formado por inúmeras etapas, sendo compra, manufatura, estoques e vendas. Com isso o desejo do mapa de fluxo de valor é tornar a empresa mais ajustada possível, por meio de uma produção puxada.

Figura 1 - Mapa do fluxo de valor atual da empresa

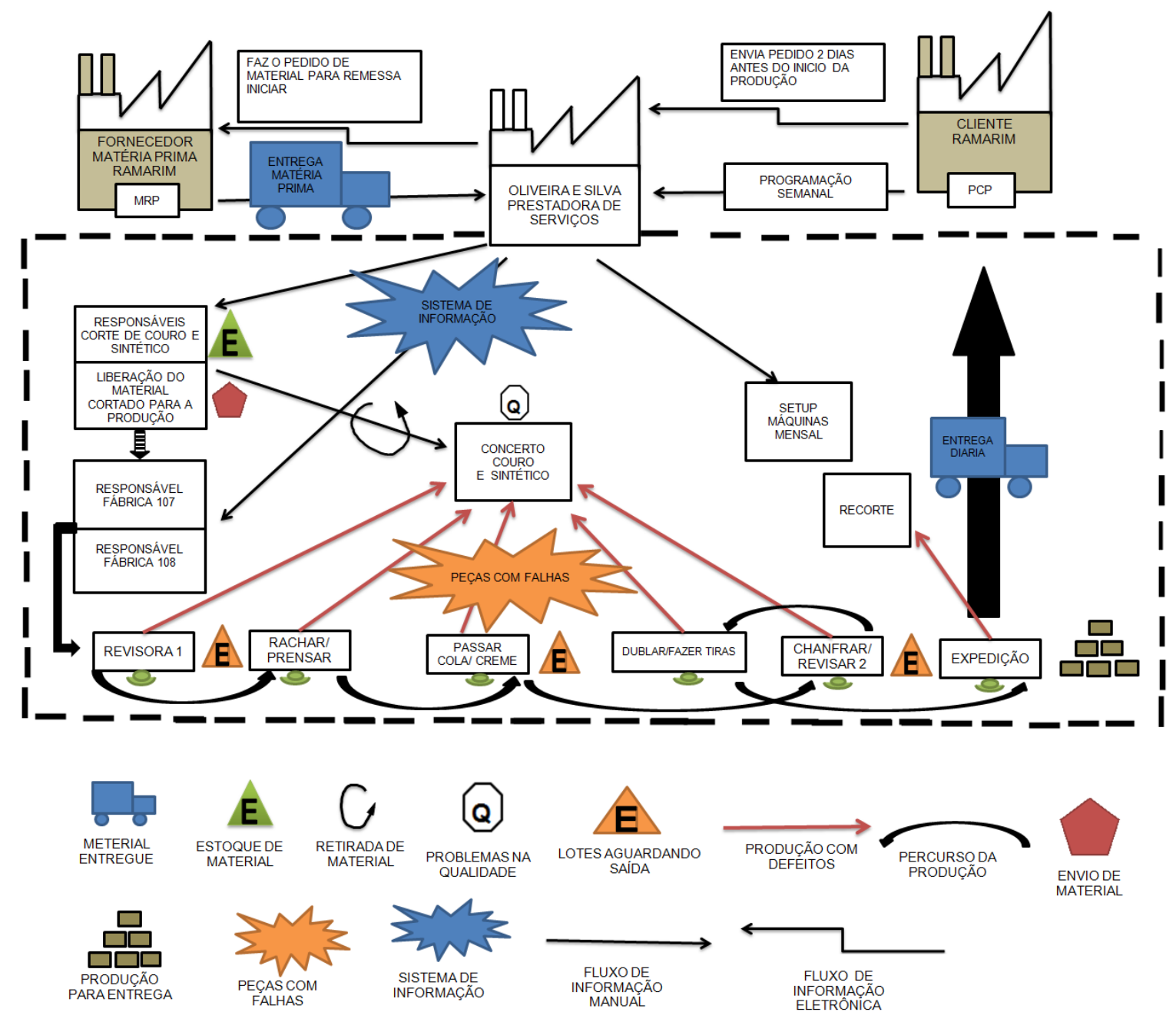

Fonte: Os autores.

Conforme a análise realizada diretamente na empresa sistemista, foram identificados os pontos de percurso e transformações dos produtos com finalidade para formação do cabedal. Ilustrase na Figura 1 um resumo do fluxo atual da indústria quanto a seus macro processos e operações e alguns detalhes observados a falhas e gargalos que limitam a capacidade final da produção, percebíveis durante as ações e atividades elaboradas observadas diretamente na linha de fabricação.

A sistemista não se utiliza de nenhuma técnica e área de planejamento e controle de produção (PCP), pelo fato da programação vir definida diretamente da empresa âncora. Dessa forma é perceptível notar um sistema de informações básico na fábrica são oriundos dos 
planejamentos programados externamente. Como resultado desta falta de gestão interna se observou processos de superprodução, produção empurrada, ocasionando assim lotes de estoque em espera alocados em quase todas as operações.

Neste desenho, algumas falhas podem ser notadas na sistemática de fabricação, como os setups de correção, que são realizados durante os processos, norteando a capacidade da fábrica, ou seja, inúmeros lotes que aguardam na expedição por causa destes defeitos operacionais, muitos ocasionados por falta de inspeção rotineira individual dos funcionários.

\subsection{Mapeamento do fluxo nas operações de corte}

Durante o trabalho em campo, notou-se uma disparidade na fábrica quanto ao número de concertos de material em couro natural e sintético, que havia durante os processos. Com isso, estes dados foram coletados primariamente por meio de planilhas entregues aos funcionários de cada setor.

Dar-se a importância de mensurar estes dados coletados sobre quantidade de concertos realizados, porque informam a perda produtiva da fábrica, ou seja, a quantidade de pares dias que está sendo desperdiçada por meio de solução de falhas.

Figura 2 - Mapeamento do fluxo em concerto de couro
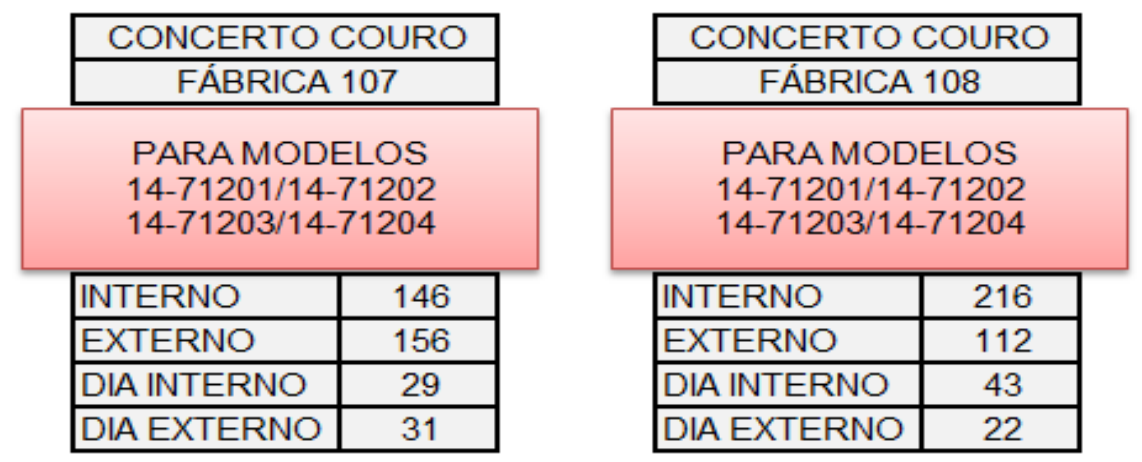

Fonte: Os autores.

O que se nota na Figura 2, são dois tipos de informações, sendo concretizados por um controle semanal, com os quatro modelos base estudados na pesquisa, para fábrica de linha $107 \mathrm{e}$ 108. Como resultados obtidos por meio de uma média estimada, para linha 107 foram considerados 146 peças concertados internamente na produção por semana, sendo 15 pares dia, com porcentagem que interfere na fabricação da linha em $1,25 \%$ dia.

Os concertos externos são providos da empresa âncora que solicita a fábrica para cortar peças que foram falhas externas, neste fato este processo interfere nos tempos da indústria, sendo responsável por uma estimativa de 156 peças concertadas por semana, destes 16 pares dia, com porcentagem de interferência na produção de $1,33 \%$ dia. 
Em relação a concertos internos ocorridos na linha 108 identificou-se 216 peças por semana, 22 pares dia e influência na produção em porcentagem de 1,83\% dia. Externamente originou-se 112 peças semana, dentre estas 11 pares por dia e com influência de porcentagem de 0,92\% dia.

Sabe-se que a influência do MFV é identificar as falhas, os pontos de gargalos originários na produção, com isso a ressalva importante para estes dados coletados se dá por meio de uma previa estimativa de como é a tendência mediana da fábrica quanto a desperdícios e falhas.

Neste contexto o prognóstico da realização da pesquisa, indaga-se que a indústria apresenta perdas de aproximadamente $3,08 \%$ ao dia com possíveis falhas oriundas das operações das linhas 107 e 108, em comparativo com a demanda de 2.400 pares dia, 74 peças ou 37 pares, são retrabalhos.

Comentado sobre falhas externas ao qual não tem interferência direta na sistemática da produção 107 e 108, a avaliação ocorre por meio de 2,25\% dia em concertos, ou seja, conforme a capacidade total produtiva da fábrica, 54 peças ou 27 pares por dia.

As falhas externas resultam em uma perda significativa de tempo na fábrica, o que torna complicado de se mensurar porque são oriundos da empresa âncora, já os concertos internos interfere no tempo, qualidade, movimentos e na capacidade da fábrica no momento da fabricação dos produtos.

O porquê das falhas externas serem entregues para a sistemista efetuar os processos, é que a empresa âncora monta alguns modelos em menor escala no interno da fábrica, sendo estes terceirizados. Observa-se que para cada par, estimam-se nove operações, e cada uma destas com tempos de balanceamento, ou seja, em configurações de retrabalho 37 pares equivalem 333 operações em tempo que foram perdidos e 27 representam 243 operações. É de fácil entendimento captar que estes dados apresentam uma preocupação significativa à fábrica.

Tabela 1 - Mapeamento do fluxo em concerto de sintético

\begin{tabular}{c|c|c|c}
\hline \multicolumn{3}{c}{ Concerto de sintéticos das fábricas 107/108 } & Cortadores \\
\hline Peças internas & Peças externas & Produção & X \\
\hline 427 & & & X \\
\hline 1398 & 372 & & 2.197 \\
\hline & Total de concertos mês & 439 \\
\hline
\end{tabular}

Fonte: Os autores.

Para o sistema de corte em sintético é diferente do couro natural, porque no sintético uma navalha de corte faz até seis peças simultaneamente, sendo que para o couro corta-se somente uma peça a cada batida dos balançinhos. 
Esta sistemática de operação resulta em uma tendência alta em concertos no material sintético quando ocorre uma falha no corte. Pelos dados coletados na Tabela 1 esta análise estima que 427 peças apresentem defeitos em suas operações na produção pós corte por semana para as linhas 107 e 108 .

Sendo assim uma navalha do sintético equivale a seis peças, que são três pares, a divisão segue em estimativa de 143 pares por semana, e ao dia, 29 pares, com alavancagem de 1,21\% de interferência, ou seja, 29 x 100/2400 (fab. 107 e fab. 108). Os defeitos diretos oriundos dos cortadores foram de 1398 peças, sendo estimados 466 pares por semana ou 93 pares dias, um pressuposto de $3,88 \%$ de falhas ao dia.

Com estas duas porcentagens do sintético, a influência é de 5,09\% ao dia. Já para peças externas, em que foi avaliado como produção porque desdenha da empresa âncora ocasiona 372 peças ou 124 pares por semana, que representa 1,04\% dia na capacidade da fábrica. Em pressuposto, são duas máquinas distintas com operações caracterizadas, sendo uma para material de couro e a outra para sintético, com a distinção de inúmeras navalhas, na qual estas foram para realizar os modelos base.

\subsection{Análises de Setup das máquinas}

O setup é um evento que não agrega valor diretamente na produção da empresa. Na busca da otimização, pensar um sistema que auxilia na troca de ferramentas, com o intuito de reduzir os tempos ociosos quanto a paradas inesperadas na fábrica ou na possibilidade de início mais breve do processo produtivo é um dos focos principais do seu estudo (SINGO, 1996).

Quadro 2 - Setup das máquinas

\begin{tabular}{|c|c|c|c|c|c|}
\hline \multicolumn{6}{|c|}{ Setup de tempo nas máquinas de produção } \\
\hline Tempo/min & Periodo & \multicolumn{2}{|c|}{ Interferência produção } & \multicolumn{2}{|c|}{ Não interfere na produção } \\
\hline 60 & 21/ago & & & \multicolumn{2}{|r|}{ Não } \\
\hline 270 & 21/ago & & Sim & \\
\hline 150 & 22/ago & & & \multicolumn{2}{|r|}{ Não } \\
\hline 30 & 25/ago & & Sim & & \\
\hline 30 & 25/ago & & & \multicolumn{2}{|r|}{ Não } \\
\hline 80 & 26/ago & & & \multicolumn{2}{|r|}{ Não } \\
\hline 40 & 26/ago & & Sim & \\
\hline 160 & 27/ago & & & \multicolumn{2}{|r|}{ Não } \\
\hline 30 & 27/ago & & Sim & & \\
\hline \multicolumn{2}{|c|}{ Total tempo min para 5 dias } & & 850 & \multicolumn{2}{|c|}{ Interferência produção em \% } \\
\hline \multicolumn{2}{|c|}{ Não infuência prod. min. para 5 dias } & & 480 & & $56 \%$ \\
\hline \multicolumn{2}{|c|}{ Influência na prod. min. para 5 dias } & & 370 & & $44 \%$ \\
\hline \multicolumn{4}{|c|}{ Tempo estimado na influência produtiva } & & rox. $74 \mathrm{~min} / \mathrm{dia}$ \\
\hline \multicolumn{4}{|c|}{$\begin{array}{l}\text { Perda estimada de produção em quantidade conforme a média dos } \\
\text { "modelos base" }\end{array}$} & \multicolumn{2}{|c|}{ Aprox. 19 pares/dia } \\
\hline Modelo 14-71/201 & \multicolumn{2}{|c|}{ Modelo 14-71/202 } & \multicolumn{2}{|c|}{ Modelo 14-71/203 } & Modelo 14-71/204 \\
\hline Tempo para 12 par & \multicolumn{2}{|c|}{ Tempo para 12 par } & \multicolumn{2}{|c|}{ Tempo para 12 par } & Tempo para 12 par \\
\hline Aprox. 40 min. & \multicolumn{2}{|c|}{ Aprox. $49 \mathrm{~min}}$. & \multicolumn{2}{|c|}{ Aprox. $36 \mathrm{~min}$. } & Aprox. $58 \mathrm{~min}$. \\
\hline
\end{tabular}


Neste assunto foi utilizada uma planilha semanal com acompanhamento junto ao responsável pelo setor no qual os resultados obtidos estão informados no Quadro 2.

A utilização desta ferramenta na Calçados Oliveira é realizada pelo modo de supervisão uma vez ao mês, e para as demais situações os defeitos vão ocorrendo e com isso é realizado o Setup de correção. Para isso o instrumento básico utilizado foi uma planilha de controle, com os modelos base de pesquisa, no qual os dados alcançados forma apresentados no Quadro 2.

Com as informações levantadas na pesquisa, estima-se que a empresa possa ter uma perda em máquinas paradas, ou seja, tempos e produção ociosa em estimados 19 pares/dia. Com este valor a fábrica pode acarretar em ociosidades maiores se for levado em conta estes dados ao mês, no que pode mensurar aproximados 308 pares/mês.

\subsection{Análises de eficiência}

Estes dados favorecem um entendimento que como está a situação da empresa, quanto a cálculos realizados por meio de número de pessoas, valores por pares produzidos, tempo de cada processo e quantidade de produção.

A importância desta informação, busca mencionar aos gestores da fábrica sistemista e âncora, como encontra-se a capacidade diária de produção. Observa-se no Quadro 7 o método utilizado para o controle total sobre os quatro modelos e a produção final de cada um em processo diário.

Quadro 3 - Eficiência da produção

\begin{tabular}{|c|c|c|c|}
\hline Corte Fab. 107 & Tempos & Produção & M. Produt. \\
\hline $14-71201$ & 7,562 segundos & 99 & 0 \\
\hline $14-71202$ & 9,844 segundos & 0 & 4738,64 \\
\hline $14-71203$ & 8,402 segundos & 464 & 6165,43 \\
\hline $14-71204$ & 13,174 segundos & 20 \\
\hline \multicolumn{2}{|c|}{ Cessoas necessárias para realizar a produção para os modelos } & 1200 unidades \\
\hline \multicolumn{2}{|c|}{ Enficiência para essa produção } & 1.131 unidades \\
\hline
\end{tabular}

Fonte: Dados fornecidos pela empresa.

Nota-se também que a eficiência está em 94,25\%, ou seja a meta de 1.200 pares no corte 107 não foram alcançadas sendo necessário buscar no próximo dia 5,75\% restante, esta porcentagem é cumulativa.

Estes dados são gerados também para se ter informações de giro de produção. Como no caso da fábrica que estava com um giro produtivo de 7,68 dias para realização de toda produção da remessa 14-71201 a 14-71204.

\subsection{Análise do layout atual}

Sabe-se da dinâmica que apresenta a fábrica, conforme as constantes modificações de acordo com as demandas. Em conformação de apurar o layout da fábrica, a análise explanou-se por 
meio de diálogos entre os colaboradores e gestores, o que passou uma percepção de como permanece a indústria no seu layout atual.

Pode-se explanar que a fábrica utiliza de um método de layout por processo funcional, a que se refere em uma movimentação da produção flexível, com a adequação do material de acordo com a localização das máquinas. Este modelo é importante para as indústrias que se utilizam de constantes mudanças de linhas produtivas como a de setor de calçados entre outros setores.

Para este trabalho, originou-se um esboço empírico de como é efetivado todos os traslados dinâmicos de produção os caminhos percorridos desde seu início até o momento da expedição, no que tange o dinamismo das operações, mas dos processos, assim percebidas na Figura 8.

\subsection{Análises sistemáticas das operações e processos}

De acordo ao contexto, Corrêa (2007) explana a questão do fluxo contínuo o qual propõe uma sequência dos processos e operações de um produto específico, ou seja, os equipamentos devem ser inseridos próximos, norteando a produção empurrada para puxada o que supostamente deve manter um estoque de linha quase zero (KRISTENSENA; ISRAELSENB, 2014; MARODIN; SAURIN, 2015)

Figura 4 - Estoque de linha zerada
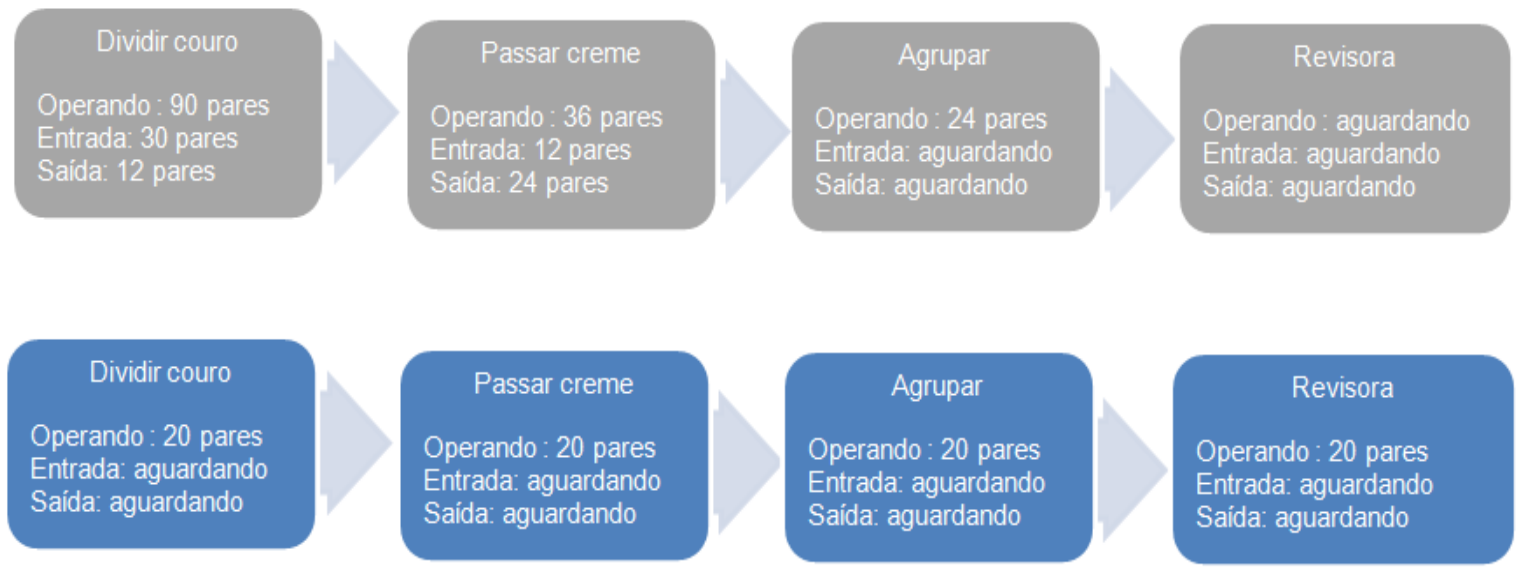

Fonte: Os autores.

A casualidade de não estar acontecendo à sistemática atual, é motivada por falta de matéria prima ou máquinas em concerto. Os gestores de produção decidem interferir em algumas operações para não deixar lotes sem processamento.

Esta abordagem em lotes é observada na Figura 4, que define o alinhamento sistemático, abordando os quatro setores em operação de forma diferenciada, com recebimentos e saídas, sem identificação de quais lotes âncoras estão circulando. 
Outra representação é realizada com base no balanceamento, no entanto produz-se 20 pares, entregando somente os 20 pares, não interrompendo o ciclo pondo os posto que já tenham terminado a produção em aguardo.

Assim, diante do pensamento sistemático, as operações que incorporam o setor de corte e chanfro da fábrica, é apontada de acordo a Figura 5 que corresponde a sistemática dos processos e operações, podendo contar com 8 técnicas manuais e 9 com máquinas para ambas as linhas 107 e 108, em que a qualquer momento operações podem ser removidas e inseridas.

Figura 5 - Sistemática dos processos e operações

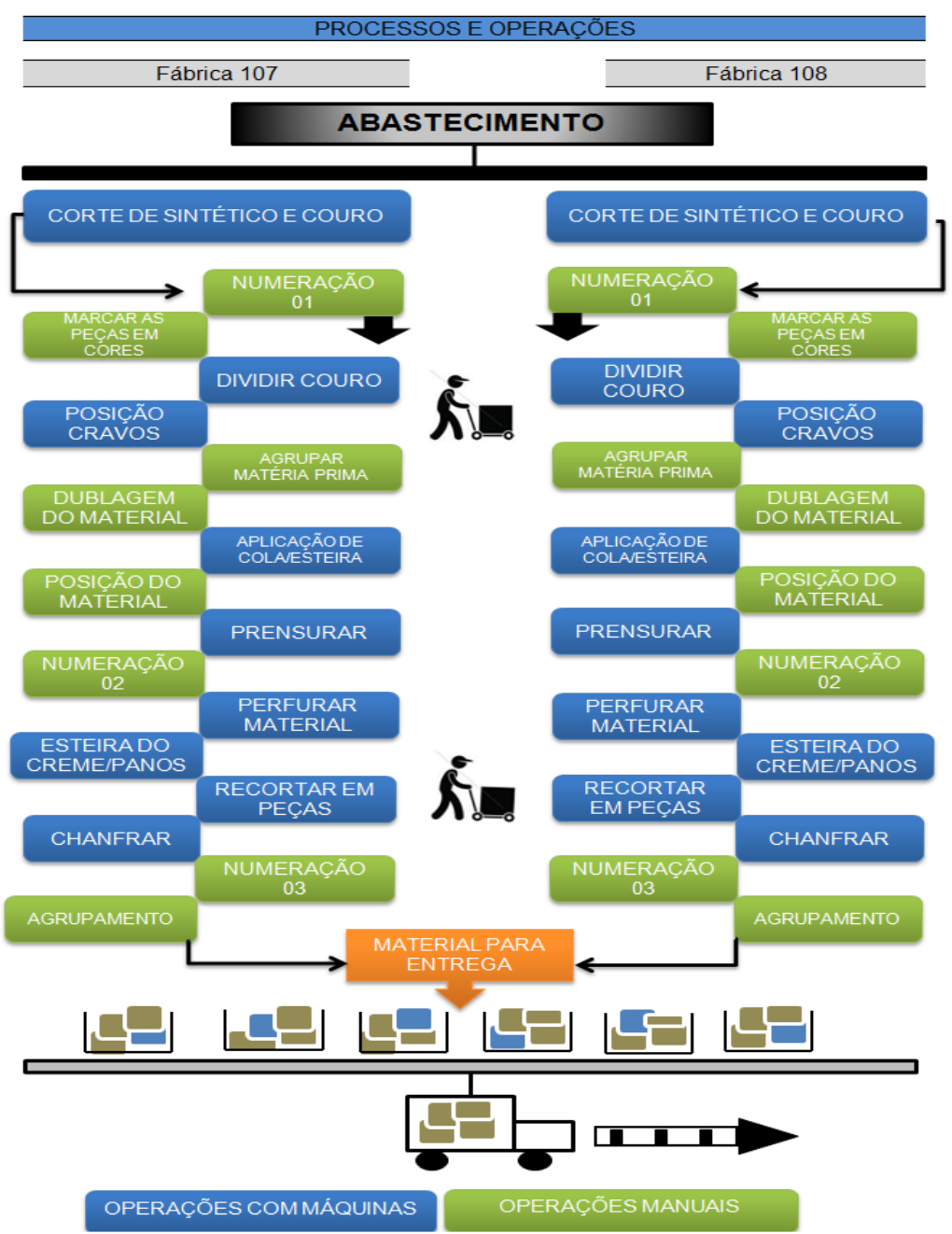

Fonte: Os autores.

Para Moreira (2008, p. 10) "produção contínua ou fluxo em linha apresentam uma sequência linear para fazer o produto ou serviço, os produtos são bastante padronizados e fluem de um posto de trabalho a outro em uma sequência prevista". 


\subsection{Identificação de gargalos na produção}

Uma das etapas talvez mais importantes do mapa de fluxo de valor é a identificação dos pontos que se apresentam como gargalos. Para isso a Figura 6, em que representa distintas fotos retiradas de pontos internos na organização com falhas, em que a natureza destes pontos é influenciada por inúmeras deficiências na produção, sendo possível serem medidas por meio dos funcionários e máquinas.

No estudo constatou que três setores da fábrica necessitam de cautela. Para isso o primeiro gargalo localizado resultou na conclusão de que os responsáveis pelo setor de recebimento do material para as remessas conferem a matéria prima, e mesmo se estiver faltando alguma pele de couro ou rolos de sintéticos, envia-os assim mesmo para início da produção.

Figura 6 - Identificação dos gargalos

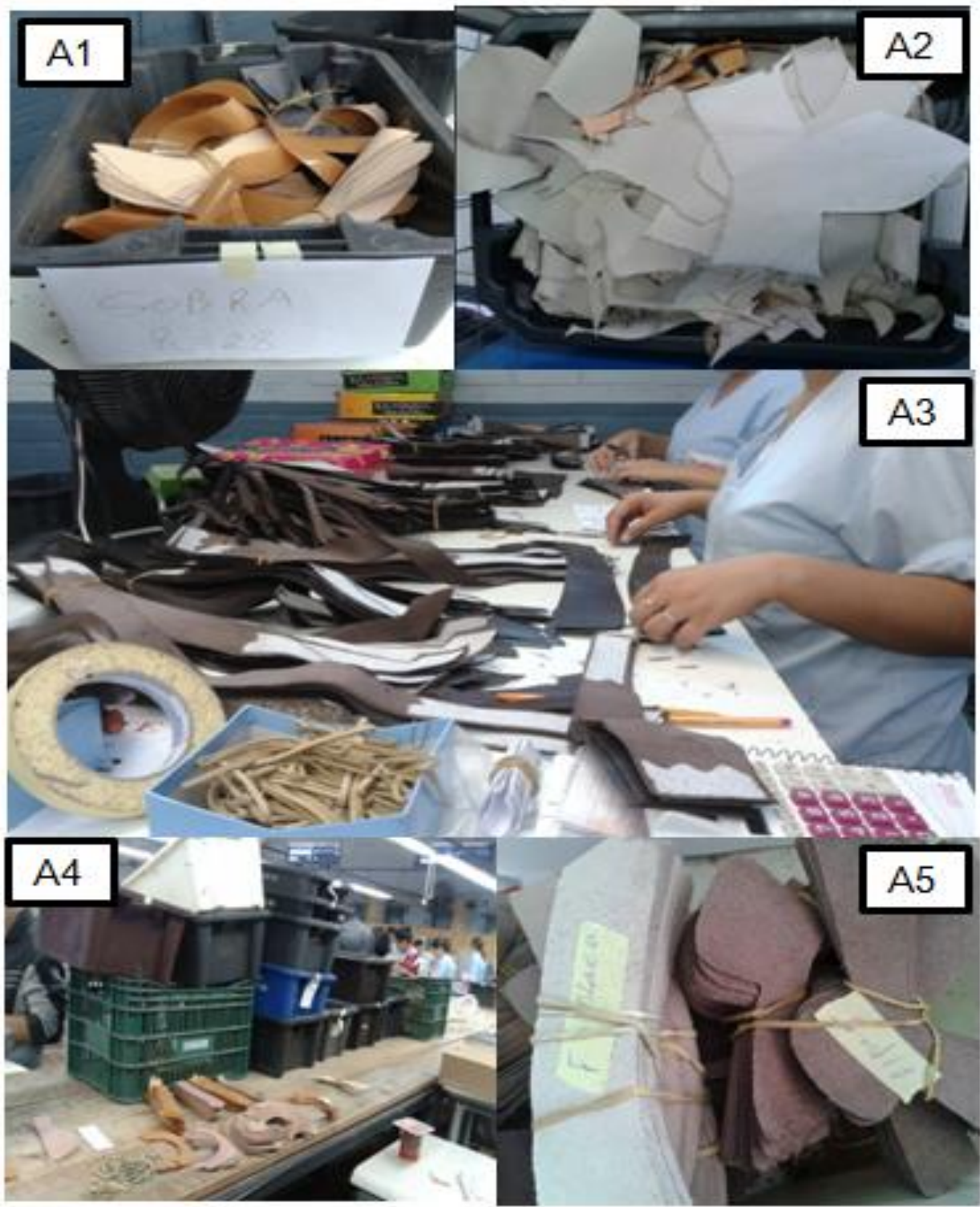

Fonte: Os autores. 
Este gargalo citado quanto ao recebimento de material, implicou em determinados momentos algumas paradas na produção e quebra de lotes que foram notadas nos testes de acompanhamento.

Muitas destas implicações quanto a paradas na produção ocorrem porque, o setor de conferência e recebimento recebem ordens para inserir mesmo faltando o material e supostamente permanecendo em status quo, aguardando a chegado do pedido quanto à falta de material.

Em expressar o segundo gargalo as distorções encontradas para o setor de corte são de retrabalhos. Por meio de análises, para um funcionamento melhor da fábrica necessitaria que os cortadores estivessem com a fabricação pronta um dia antes de iniciar qualquer remessa.

Diante disso outra distorção verificada foi o setor de revisão do pós corte. Este setor ao receber os lotes com peças em falta na caixa, não são conferidas e são passadas para frente, ou seja, como não há uma sistemática vigente de verificação individual dos lotes, a probabilidade é que percorram todas as operações em falta, permanecendo parados quando for checado nas revisoras de conferência final para expedição.

A estratificação das imagens representadas por fotos A1 e A2, ilustradas dentro da Figura 11, são proporções de sobras de material ocorridos em 12 dias de acompanhamento de dos modelos 14-71201 a 14-71204. Poucas destas sobras são reaproveitadas, porque são peças especialmente concretizadas para estes modelos não podendo ser utilizadas em outros por distintas semelhanças como cores, tamanhos e estilo de material utilizado, com isso é realizado o descarte.

Para o setor de revisão, nota-se uma organização distorcida, fato que pode acarretar em perda de tempos e movimentos pelos distintos modelos inseridos nas mesas, no que a percepção em diferenciar é realizada pelos piques que tem cada peça.

Por fim, quanto à movimentação dos lotes a foto A4, exibe algumas caixas paradas com algumas esperando por material ou peças com defeitos que estão para o concerto. E na foto A5 mostra em dois lotes parados como é realizado o processo de identificação quando falta alguma peça no mesmo, sendo muitas vezes as revisoras de liberação que observam estes pontos.

\section{Diagnóstico como propostas para melhorias do mapa de fluxo de valor futuro}

Qual importância do Mapa de Fluxo de Valor para Atelier de corte e chanfração? Após os estudos aplicados e gerações de ideias, notou-se conforme a Figura 7 que não é fácil estruturar um sistema que gere informações capazes de suprir as necessidades da fábrica imediatamente e simplificada, porque há muita coisa a adaptar-se no ambiente manufatureiro.

Com isso, dar-se o trabalho de buscar melhores informações de mercado externo antes de impor alguma alteração interna. Comenta-se este fato porque notavelmente há alguns anos, é o 
mercado que indica como a empresa tem de trabalhar, as mudanças devem primeiramente vir de fora do portão da indústria para o interno.

Mas, por meio deste diálogo, em como sobrepor um sistema em uma empresa que adota um método de trabalhar diferente do que se espera aplicar, é que buscou-se a importância de abordar um novo Mapa de Fluxo de Valor (MFV) que poderá auxiliar como proposta de melhorias para todo o setor produtivo e administrativo da organização.

A nova abordagem do mapa, explana questões de melhorias para o setor de fluxo de informações manual interligados, sendo para esta área precisa ser mais fundamentada internamente quanto a tomadas de decisões, prestando feedback para os setores. Há uma nostalgia emergente que precisa ser fluída ante as gestões, por meio de reciprocidade interna, em que o elo de comunicação não pode ser quebrado.

Com isso, apontar como esta à fabricação ao dia, pode ser implementado com painéis Kanban visíveis, para que todos os colaboradores possam perceber o nível da situação e assim poder motiva-los a trabalhar pela empresa.

O sistema Kanban, auxiliaria a empresa no quesito em organização dos lotes, identificandoos em quais operações estão e se foram finalizados, é um controle do percurso do lote desde início ao fim da produção, podendo ser inserido em pontos que emergem os gargalos especificamente.

Nas características do sistema Poka-Yoke, talvez seja o de grande resultado ao ser implantado na fábrica, porque seu sistema é atribuído aos colaboradores nomeadamente, no qual tem como missão identificar e diagnosticar peças com defeitos.

Foram então percebidos que, distintos colaboradores não elaboravam esta técnica de inspecionar o que está sendo produzido, ou seja, caso a implantação seja efetivada, acredita-se neste processo uma queda de tempos e peças com defeitos.

Para a fábrica que utiliza um balanceamento e layout disponibilizado pela Ramarim, foram percebidos que muitos destes processos podem ser modificados no âmbito produtivo, com novas formas e atribuições de técnicas para desempenho, por meio de uma aplicação de (PCP) planejamento e controle de produção, ligado diretamente à gestão de produtividade.

Observando no mapa futuro, se estabelece uma recolocação do layout fixo de máquinas, porque os processos são os mesmos independentes do modelo, o que pode mesclar são as operações que são dinâmicas, esta recolocação pode ser otimizada com um balanceamento por meio do Takt Time atribuído de uma quebra de lotes econômico.

Explanado sobre setup das máquinas, a sistemista poderia analisar o caso com mais importância. Nos controles adotados para coleta de dados na produção notou-se a disparidade em proporções de tempos e quantidade, por meio de máquinas que ficam paradas no momento que devem estar trabalhando. 
Sugere a organização um setup preventivo, no qual o responsável faz uma conferência de todas as máquinas no período da manhã antes de iniciar o trabalho e uma inspeção no final do dia após o encerramento. É notável que a probabilidade de ganho em tempo quanto à capacidade de produção poderá aumentar.

Figura 7 - Mapa de fluxo futuro

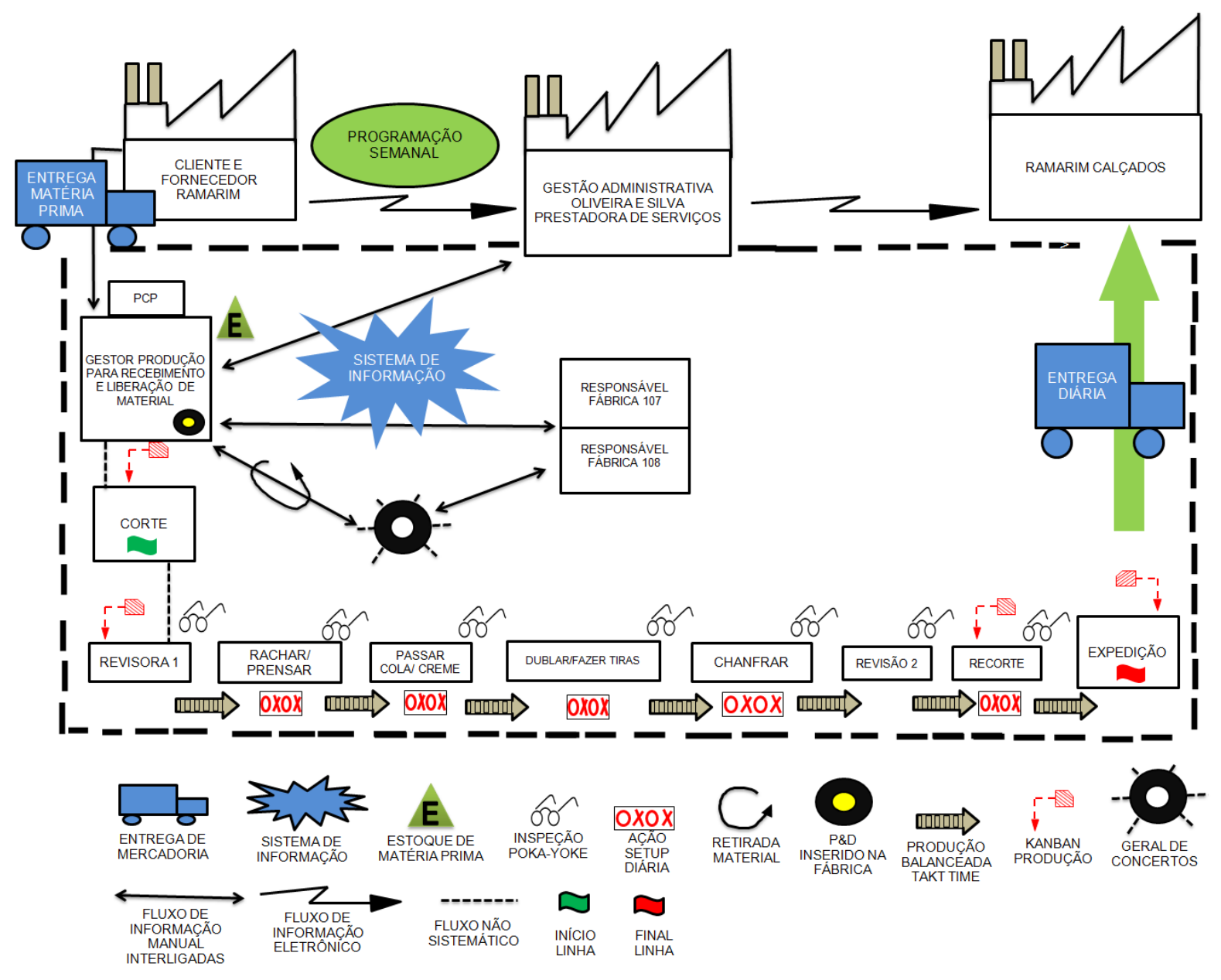

Fonte: Os autores.

Por fim, acredita-se que o setor de concertos poderá ser solicitado em menor frequência após esta aplicação com isso no mapa de fluxo de valor ficou interligado aos responsáveis pelas linhas 107 e 108 e aos gestores de produção. A inovação quanto a P\&D, é uma ferramenta essencial para qualquer organização que busque novos produtos e novas metodologias que possam ser eficiente operacionalmente, com isso solicitou a aplicação acompanhado dos gestores para que possam barganhar informações sustentáveis. 


\subsection{Diagnóstico no fluxograma horizontal de gargalos manufatureiros}

Talvez uma das premissas do sistema Lean manufacturing, é a localização de "gargalos" ou defeitos, que podem ser percebíveis no mapa de fluxo. São nestes defeitos muitas vezes não notadas pela organização.

Com os estudos ampliados, e atenção dobrada para identificar as causas e as deficiências visíveis na fábrica, percebeu-se por meio dos dados a fragilidade em três setores, mas mais importantes, mas sim, considerado gargalos.

Figura 8 - Fluxograma de gargalos

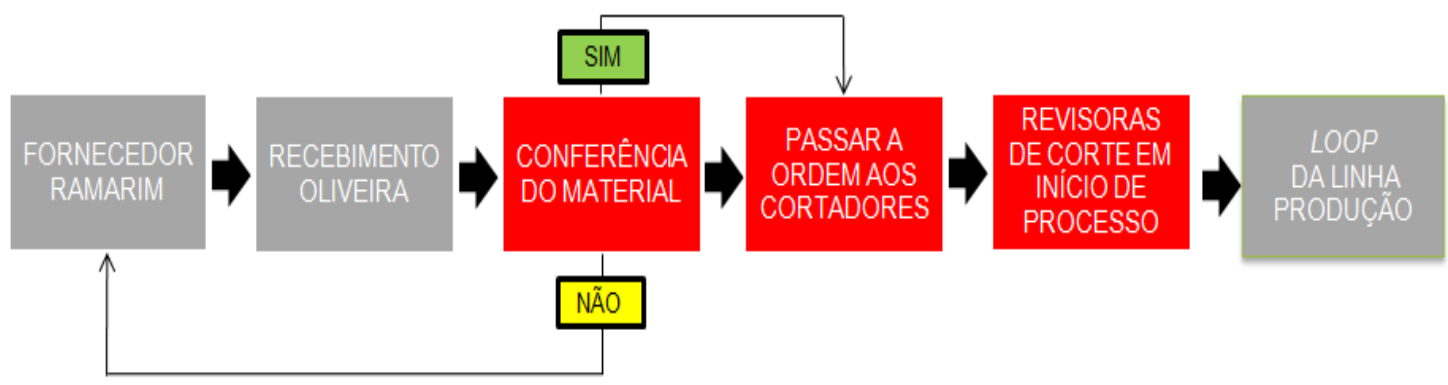

Fonte: Os autores.

O sistema Lean Manufacturing, faz esta capitação de dados e os auxilia quanto às decisões cabíveis. Para isso o setor encontrado como Gargalo 1, expressou-se no recebimento de material. Por ventura, esta operação tem a autonomia de emergir ordens cabíveis de melhorias, embora a empresa âncora monopolize este setor pelo fato de entregar a matéria prima.

Talvez, a solução seja simples de aplicação sem a necessidade de sistemas burocráticos, e é como apresenta a Figura 8, se o material que acabou de chegar não estiver $100 \%$ para iniciar a remessa de produção, a informação precisa ser passada a empresa cedente do material e com isso neutralizar a iniciação da fabricação. A simplicidade desta aplicação inibirá operações paradas no percurso produtivo.

Já no setor de corte considerado Gargalo 2, notou-se que o setor está realizando as tarefas juntamente com a linha de produção, ou seja, no mesmo momento. Este fato pode prejudicar a linha caso alguma peça tenha de ir para concerto, e sou falte material sendo refeito inúmeros processos e desgastando todo o sistema que é para ser contínuo.

Notifica-se com esta consideração que o essencial seria a inserção do setor de corte com a produção de um dia anterior ao início da remessa, mas para isso o PCP da empresa precisa ser reanalisado junto a empresa âncora para consolidar a ideia.

Nota-se, que na figura apresentada os setores com dificuldades estão em sequência. Com isso o Gargalo 3, sendo o setor das revisoras é ambiente talvez não mais importante mas o que precisa ter uma eficiência diferenciada dos demais, porque caso entregue a remessa com cortes errados e ou lotes errados pode ocasionar em futuros problemas. 
Neste conceito, identificou-se que alguns materiais estavam sendo direcionados as linhas com algumas peças com defeito ou lotes faltando, e, como não há nenhuma inspeção este resultado negativo aparece na revisora final e então o lote fica aguardando liberação do que foi considerado defeito ser consertado.

Após o recebimento dos cortadores o material precisa ser altamente verificado pelas revisoras, no qual em nenhuma hipótese pode ocorrer peças erradas no sistema de produção. Como diagnóstico as revisora precisam estar interligadas ao sistema de concerto caso ocorra defeitos, e assim, corrigindo-os, e não passar adiante.

\section{Considerações finais}

Ao iniciar esta pesquisa em uma empresa sistemista de uma grande fábrica de calçados situada no município de Nova Hartz - RS norteou-se como objetivos do estudo em analisar o ambiente atual da fábrica quanto a formação de cabedal de calçados e propor algumas melhorias internas ao sistema Lean Manufacturing, composto do Mapa de Fluxo de Valor, identificando as ações que são desenvolvidas e os impactos ocasionais.

Para isso, o sistema que integrou-se na pesquisa foi com base na analogia do Toyotismo, que integralmente são métodos antigos, mas que por ventura se configuram importante nos tempos atuais, e para indústrias que não detém desta ferramenta, julga-se muito necessário, pelos fins de mercados competitivos na atualidade.

Neste contexto, ao fazer um mapeamento de fluxo de valor na fábrica, foram revelados ambientes que justificam a necessidade em agregar melhorias. Identificou-se que empresa sistemista tem uma fragilidade na produção inicialmente quanto a tomada de decisões.

Entende-se, que as decisões para as demandas cabíveis estão sendo atendidas e que a qualidade permanece em primeiro plano, e na pesquisa revela esta confirmação, mas a concretização por melhorias precisa ser perceptível ante a visão dos gestores e por meio da criatividade de seus funcionários, ou seja, apesar das mudanças propostas não serem cabíveis em curto prazo é essencial que a organização de uma sequência para concepção deste trabalho.

Com isso, em determinado momento foi identificado no qual ofusca a produção real de capacidade produtiva na organização e a proporção de concertos internos e externos, sendo assim, constatados como retrabalhos e desperdícios de matéria prima, no qual na pesquisa soma-se uma estimativa que influência a fabricação em mais de $10 \%$ ao dia, ou seja, estimadas uma hora desperdiçada por dia.

Neste pensamento uma organização que tem como vigor a utilização em tempos, valores em pequena escala, como em segundos e centavos, um retrabalho em dez minutos pode interferir na produção de até 15 pares no final do dia, são estes processos e operações ociosas que viga a ideia de 
contribuir para a fábrica pontos no qual a mesma ainda não julgou necessária uma interferência, porque o pensamento esta na produção empurrada.

Além disso, salienta-se que a organização precisa focar no balanceamento de suas operações, porque o que vem ocorrendo conforme apresenta nos gráficos em análise, é uma produção que se importa em fabricar ao máximo, exigindo de seus colaboradores qualidade, mas que pouco abrange um desenvolvimento capaz de gerir uma produção maior que os 2.400 pares por dia, com a mesma capacidade de maquinários e talvez até com a diminuição de pessoal.

No entanto, é para estes desempenhos que procurou informar a organização, que operações precisam ser revistos e se possível tomar ações que possam resultar em produção eficaz. Com isso ao estruturar um novo mapeamento de fluxo de valor, proporcionou para fábrica caminhos que possam auxilia-la ao decidir o que pretende-se trabalhar no futuro.

Para isso, o mapa apontou detalhes na sistemática quanto ao balanceamento, no qual é necessário fazer uma quebra de lotes, extinguindo as ociosidades que restringem a produtividade, e os setups corretivos precisam ser passados para preventivos, neste conhecimento a probabilidade de ganhos em capacidade de produção poderá ser maior.

Como parte destes detalhes as inspeções das peças precisam ser focadas, fazendo dos colaboradores parte do sistema, utilizando-se desta ferramenta Poka-Yoke, inibe-se a perda de material e o aumento da qualidade.

Com estas ações a partir dos resultados do mapa futuro proposto à organização, colocar em prática o sistema Kanban e Takt-Time, ajustará defeitos em balanceamentos, estoque e lotes em quase zeros, disciplinando principalmente o crescimento dos colaboradores quanto à responsabilidade em realizar novas técnicas.

Em de acordo com a pesquisa, poderá auxiliar a organização em procurar novos horizontes de gestão de seu negócio, adotando-se de uma sistema capaz de propor evoluções administrativas e produtivas a fim de mantê-la como forte concorrente no setor coureiro calçadista.

O que poderá ocorrer em trabalhos futuros na fábrica é a inserção de ferramentas no qual a organização necessita com muita urgência tendendo a ser a utilização constante das sistemáticas Poka-Yoke, Setup e Takt-Time, com a analogia e ligação destes métodos, variáveis como material em desperdícios e tempos ociosos acarretará em melhorias.

Mas para este trabalho futuro na organização, exigirão um tempo maior de estudos e uma reestruturação quanto à cultura social dos colaboradores no que tange a cooperação de ideias novas, métodos diferentes aplicáveis na fábrica. 


\begin{abstract}
Exalts the importance of seeking innovations in processes and operations that can meet the companies and customers through offering products and services. This study measured the current manufacturing process of female shoe leather and your data tabulated in spreadsheets, proposes improvements to the current process based on the concepts of value stream mapping. This proposition is aligned with Lean Manufacturing concepts and will be used for decision making to a company systemist a shoe manufacturer. In this study, some tools have been proposed by kanban methods, the cycle time of operations, setup time, and balancing of production lines, reducing potential bottlenecks. It was found that by inserting these tools the company can provide a reduction inopportune stocks, improvement in the production process flow, reduce product quality problems which will cause better results for the organization.
\end{abstract}

Keywords: value stream mapping; lean manufacturing; production; footwear; kanban.

\title{
Referências
}

CARVALHO, D. S; RESENDE, D. P; SOUZA, N. S. H; LIMA, R. F. Implantação de um arranjo físico (layout) e sua relevância para a dinamicidade organizacional no processo de produção: revisão bibliográfica. Teresina, PI, 2010.

CONINCK, M. et al. Cerebral and cerebellar language organization in a right-handed subject with a left temporal porencephalic cyst: An FMRI study. Journal of Neurolinguistics, v. 37 p. 41-46, 2016. crossref

CORRÊA, H. L; CORRÊA, C. A. Administração de produções e operações manufatura e serviços. Uma abordagem estratégica. $2^{\circ}$ Ed. São Paulo: Atlas, 2007.

GUERRINI, F. M; BELHOT, R. V; JUNIOR, W. A. Planejamento e controle da produção. Projeto e operações de sistema. Ed. Rio de Janeiro: Elsevier, 2014.

KILIC, Z. M.; ALTINTAS, Y. Generalized mechanics and dynamics ofmetal cutting operations for unified simulations. International Journal of Machine Tools \& Manufacture, v. 104, p.1-13, 2016. crossref

KOO, P. H; KOH, S.G; LEE, W. S. Determinação simultânea de tamanho do lote e da produção da taxa em sistemas de múltiplos produtos com restrição de capacidade. Publicado em Março 2011.

MARCONI, M. A.; LAKATOS, E. M. Metodologia do trabalho científico. Procedimentos básicos, pesquisa bibliográfica, projeto e relatório, publicações e trabalhos científicos. $7^{\mathrm{a}}$ Ed. São Paulo: Atlas, 2010.

MARODIN, G. A.; SAURIN, T. A. Classification and relationships between risks that affect lean production implementation. Journal of Manufacturing Technology Management, v. 26 n.1 p. 57 - 79, 2015. crossref

MARTINS, P. G.; LAUGENI, F. P. Administração da produção. 2ª Ed. São Paulo: Saraiva, 2006.

MIZOGUCHI, M. R. S.; JARDIM, E. G. M.; COSTA, R. S. A programação e o controle da produção em ambiente de incerteza e ativos caros: o caso de uma empresa termoplástica do pólo industrial de manaus. Revista Gestão Industrial. v. 06, n. 04: p. 110-132, 2010. crossref 
MOREIRA. D. A. Administração da produção e operações. $2^{a}$ Ed. São Paulo: Cengage learning, 2008.

OHNO. T. O sistema Toyota de produção. Alem da produção em larga escala. Trad. Cristina Schumacher. Porto Alegre: Bookmam, 2006.

OLIVEIRA, J. C. G. Estudo dos tempos e métodos. cronoanálise e racionalização industrial. 2012. Disponível em: <http://www.administradores.com.br/artigos/negocios/estudo-dos-tempos-emetodos-cronoanalise-e-racionalizacao-industrial/63820/> Acessado em: 8 jun. 2016.

PATTANAIK. L. N; SHARMA. B. P. Implementação de manufatura enxuta com layout de celular: Um estudo de caso. Anais eletrônicos. London: Manuf. Techno. Disponível em: < http://link.springer.com/article/10.1007/s00170-008-1629-8>. Acesso em: 8 jul. 2016.

PEINADO, J; GRAEML, A. R. Administração de produção e operações industriais e de serviços. Curitiba: Unicemp, 2007.

RITZMAN.L.P; KRAJEWSKI.L.J. Administração da produção e operações. Ed. São Paulo: Pearson, 2004.

ROTHER, M; SHOOK, J. Aprendendo a enxergar, mapeando o fluxo de valor para agregar valor e eliminar os desperdícios. São Paulo: Lean Institute Brasil, 2003.

SHINGO, S. O sistema Toyota de produção. Do ponto de vista da engenharia de produção. $2^{\mathrm{a}}$. Ed. Porto Alegre: Bookman, 1996.

SLACK, N.; CHAMBERS, S; HARLAND, C; HARRISON, A; JOHNSTON, R. Administração da produção. São Paulo: Atlas, 1999.

THANKI, S. J.; THAKKAR, J. Status of lean manufacturing practices in Indian industries and government initiatives A pilot study. Journal of Manufacturing Technology Management, v. 25 n. 5 p. $655-675,2014$. crossref

TUBINO, D. F. Planejamento e controle da produção. Teoria e prática. $1^{\text {a }}$ Ed. São Paulo: Atlas, 2007.

SOUZA, L. C.; RACHID, A. Production Management and Employees - A Survey of Auto Parts Companies. Revista de Administração Mackenzie, v. 17, n. 2, p. 211-244, 2016. crossref

VEIGA, C. H. A; CERESA, D. Mapeamento do fluxo de valor do desenvolvimento de mostruários: uma investigação em uma indústria de confecções. Redige, 2013.

VILAR, F. M. M.; SANTOS, L. C.; GOHR, C. F.; MARCELINO, M. Métodos para avaliação da produção enxuta: revisão e análise crítica. Revista Gestão Industrial. v. 12, n. 01: p. 01-23, 2016.

WEGNER, R. S., et al. Identificação do takt time de fluxo operacional de uma empresa fabricante de cabedal de calçados. In: FÓRUM INTERNCIONAL ECOINVAR, 5, 2016, Santa Maria. Anais..., Santa Maria: Editora UFSM, 2016.

WU, J. T. et al. Hesitant Fuzzy Linguistic Multicriteria Decision-Making Method Based on Generalized Prioritized Aggregation Operator. The Scientific World Journal, p. 16, 2014. crossref 


\section{Dados do autores:}

Nome completo: Wagner Pietrobelli Bueno

Mestrando em Engenharia de Produção PPGEP/UFSM

Filiação institucional: Universidade Federal de Santa Maria - UFSM

Função ou cargo ocupado: Estudante do Programa de Pós-Graduação em Engenharia de Produção

Endereço completo para correspondência: Rua. João Machado Soares, 1240 ap. 319

Bairro: Camobi

Cidade: Santa Maria - RS

Fone: (55) 9647-1415

E-mail:wbpietro@outlook.com

\section{Nome completo: Cristiano Henrique Antonelli da Veiga}

Doutor em Educação nas Ciências, Mestre em Engenharia de Produção, Administrador

Filiação institucional: Faculdade de Gestão e Negócios - Universidade Federal de Uberlândia UFU

Função ou cargo ocupado: Professor Adjunto - Área de Operações e Sistemas

Endereço completo para correspondência: Rua Divino Lucas Martins, 381 ap. 601

Cidade: Uberlândia - MG

CEP: $38408-026$

Telefones para contato: (34) 32295596

E-mail: chadaveiga@ufu.br

Submetido em: 24-10-2016

Aceito em: 31/12/2016 